\title{
Effects of Casting-Additives on the Microstructure Evolution of Hypoeutectic Aluminium-Silicon Alloys
}

\author{
Elisa Fracchia ${ }^{1, *(\mathbb{D}}$, Federico Simone Gobber ${ }^{1}\left(\mathbb{D}\right.$ and Mario Rosso ${ }^{2}$ \\ 1 Department of Applied Science and Technology (DISAT), Polytechnic of Turin, Viale T. Michel 5, \\ 15121 Alessandria, Italy; federico.gobber@polito.it \\ 2 Department of Applied Science and Technology (DISAT), INSTM c/o Polytechnic of Turin, Viale T. Michel 5, \\ 15121 Alessandria, Italy; mario.rosso@formerfaculty.polito.it \\ * Correspondence: elisa.fracchia@polito.it; Tel.: +39-0131-229-358
}

Received: 17 April 2020; Accepted: 8 May 2020; Published: 9 May 2020

\begin{abstract}
Since the industries are called to produce environmentally friendly products, the research is moving toward new improved materials. In this panorama, aluminium alloys find applications for a large range of products. In the automotive, as well as in the aerospace, sector, aluminium alloys are largely adopted, thanks to their high specific properties and their light weight. Moreover, common casting techniques permit us to realize complex high-quality components. These components may be realized by using casting techniques adopting casting-additives, such as modifiers or refiners. In this work, the effect of refining and modification was studied in terms of microstructural evolution of the intermetallic phases in two aluminium-silicon alloys (EN AC 45300 and EN AC 43500). Microstructures were analyzed through micro-hardness measures, and we found a reduction in the standard deviation of the hardness with the addition of additives. Furthermore, secondary dendrites arms spacings (SDAS) were measured, evidencing a decrease in SDAS by adding casting additives. A strong correlation was found between the adding of additives and the possibility of containing the size of the silicon and of all the intermetallic phases opening up to the possibility of tailoring the microstructures.
\end{abstract}

Keywords: Al-Si casting alloys; EN AC 45300; EN AC 43500; refining; modification; microstructure; image analysis

\section{Introduction}

In recent years, research in the fields of automotive and aerospace has made enormous progress. These advances are mainly associated with needing to reduce the environmental impact of vehicles by reducing $\mathrm{CO}_{2}$ emissions [1]. In this context, researchers have suggested many possible solutions, such as the adoption of electrical machines [2,3] or fuel cells [4]. Despite that, for the traditional engines, the reduction of fuel consumption and consequently the reduction of the weight of cars are still crucial [5]. In this perspective, thanks to their properties, especially the lightness, aluminium alloys have proved to be one of the best solutions to meet environmental needs. Aluminium alloys have high specifical mechanical properties and high corrosion resistance: These properties allow us to use the aluminium alloys in many parts of vehicles, from chassis to engine components [6,7]. Particularly, aluminium-silicon alloys are widely used in the automotive sector to realize pistons [8,9].

Unfortunately, in some applications, a component can require multiple properties that cannot be fulfilled by a single alloy. From this perspective, the usage of different alloys properly joined to each other could be useful to guarantee, for example, a change in specific properties within the piece. Since the various possible welding processes to join aluminium alloys may give rise to weak spots in the joint [10], different kinds of multi-material junctions were proposed [11-15]. On the 
other hand, multi-material solutions are difficult to implement. In this perspective, Al-Si alloys' properties can be tailored utilizing some casting-additives as the refining agents and the modifying agents [16]. This tailoring can help to customize the intermetallic phases' shape, improving the fatigue resistance, decreasing the concentration of efforts. In fact, in Reference [17], it was demonstrated that coarse intermetallic phases or acicular phases are the most prime locations for crack propagation. Refining agents act on the $\alpha$-Aluminium structures, reducing the grain size by changing the dendritic structures into equi-axial grains; moreover, the measured SDAS (Secondary Dendrite Arm Spacings) can be affected too [18], while modification agents operate on the eutectic silicon, changing its shape from acicular to fibrous or spherical shape [19]. In this work, two aluminium-silicon alloys (EN AC 45300 and EN AC 43500) were cast through gravity casting, taking care of the factor that affects the casting phase, as shown in Figure 1; alloys were studied in the as-cast state, with and without the addition of refining and modification agents, to focus the attention on the deriving microstructural changes. In particular, these alloys are of interest to the automotive sector: Alloy EN AC 45300 is adopted for realizing cylinders, engine stands, pump bodies, and compressor pistons [20], while alloy EN AC 43500 is a very versatile composition, which is characterized by a low iron tenor, suitable for applications requiring high castability in all the common casting techniques [21] (Gravity Casting GC, Sand Casting SC, High-Pressure Die Casting HPDC, and Low-Pressure Die Casting LPDC).

Additives act on these particular compositions by reducing the grain size and changing the silicon shape as for all the Al-Si alloys [22]. In particular, following the alloy manufacturer indications, it seems that 100 ppm of Al-Sr10 can be enough to properly modify the silicon shape in alloy EN AC 43500. Because the refining and modification in aluminium-silicon alloys lead to shape modification for certain kinds of intermetallic phases, such as Fe-phases and Eutectic silicon $[17,18]$, it is reasonable to think that they affect other intermetallic phases. For these reasons, the main intermetallic phases present in $\mathrm{Al}-\mathrm{Si}$ alloys were investigated in terms of micro-hardness and the occupied area, to assess the effect of the additives on the microstructural phases. Furthermore, SDAS measurements can confirm the additive effects in terms of grain refinement.

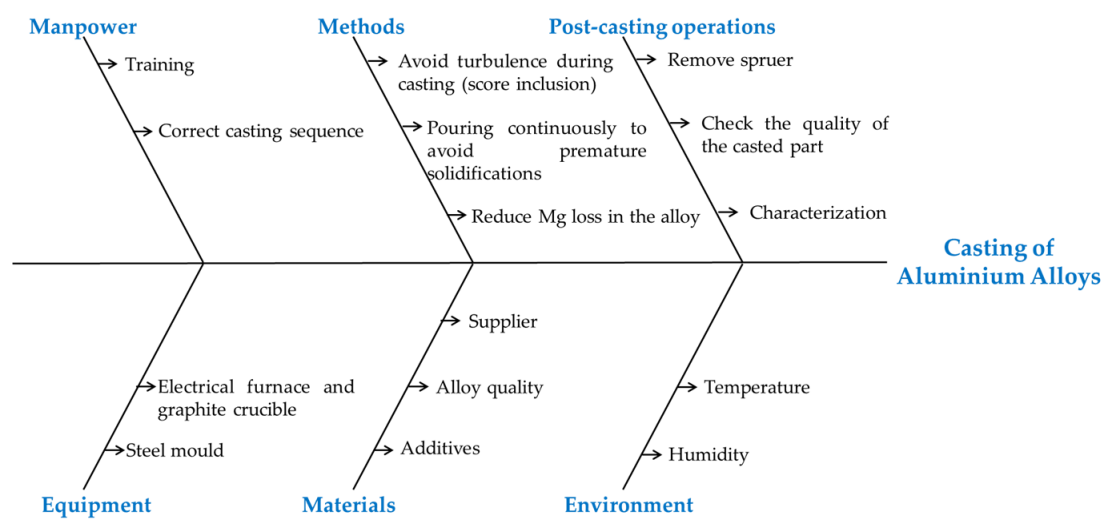

Figure 1. Ishikawa diagram: parameters affecting casting of aluminium alloys.

\section{Materials and Methods}

In this work, two aluminium alloys belonging to the Silumin group were studied; in Table 1, their compositions and their main properties are shown. Alloys were molten in graphite crucibles and cast by gravity-casting method into a preheated mould opportunely painted with a BN-stop-off paint $[23,24]$. The stop-off paint acts by reducing thermal stresses and contact with molten aluminium alloy and the steel mould $[25,26]$. In Figure 2, the casting sequence is shown: Alloys were melted into a graphite crucible and then poured into the mould. Castings were extracted after 60 seconds from the casting. Regarding the casting parameters, the alloys were melted at $710{ }^{\circ} \mathrm{C}$ in a graphite crucible and then casted into a steel mould preheated into a furnace at $400{ }^{\circ} \mathrm{C}$. Additives were added five minutes before casting, to ensure their total melting. Rectangular-shaped samples of $125 \mathrm{~mm} \times 25 \mathrm{~mm} \times 15 \mathrm{~mm}$ 
were obtained. Three bar-castings of each alloy were analyzed overall. The first casting was obtained without any casting-agent, while 250 ppm of refiner-alloy Al-Ti-B, in the form of a rod, was added to the second casting, and finally, the third cast was performed by adding both 250 ppm of the refiner-alloy Al-Ti-B and 250 ppm of modifier-alloy Al-Sr10 in the form of a rod.

Table 1. Chemical compositions and mechanical properties of the alloys according to standard UNI EN 1706 and 3600.

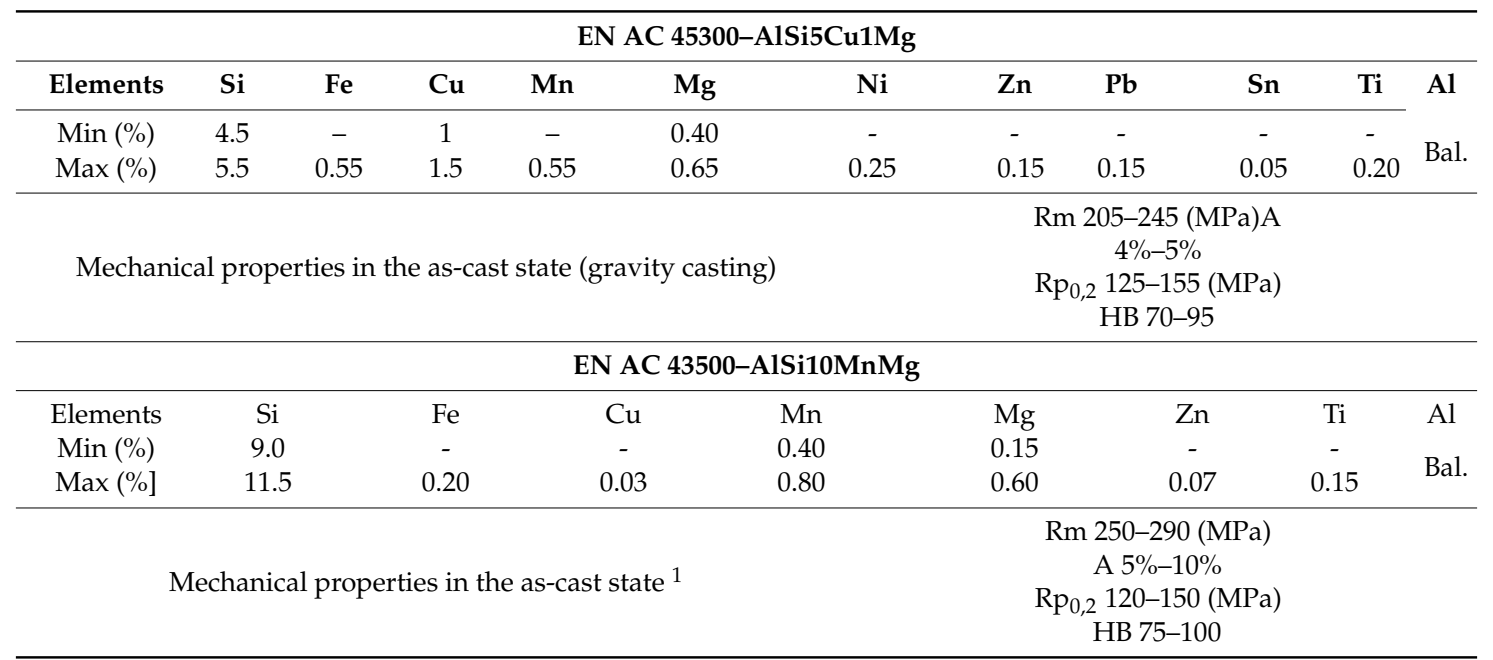

${ }^{1}$ Since this alloy is commonly adopted for high-pressure die casting (HPDC), properties in technical sheets refer to castings obtained via high-pressure die casting.

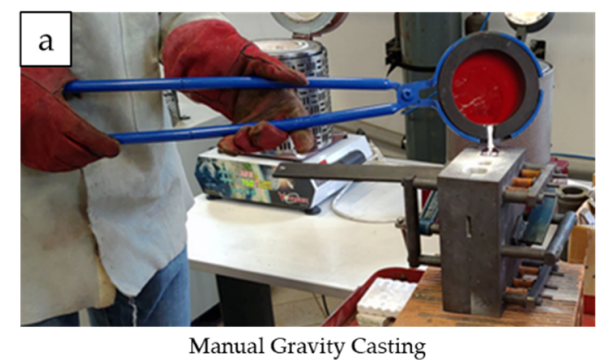

Manual Gravity Casting

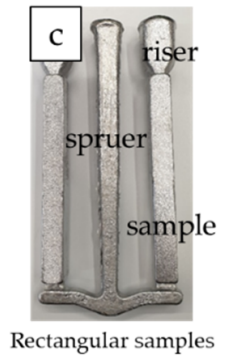

Rectangular samples

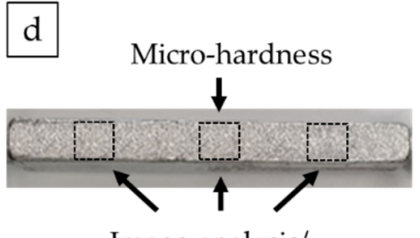

Image analysis/

SDAS

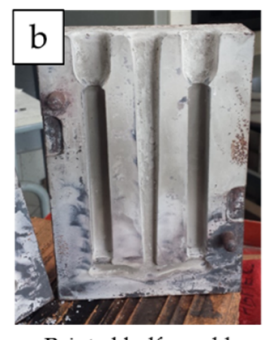

Painted half mould

Micro-hardness

scheme

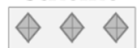

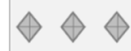

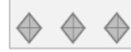

Figure 2. Casting sequence. Manual gravity casting procedure (a); mould adopted (b); Casting obtained (c) (only one rectangular-shaped sample was used); Scheme of the distribution of the micro-hardness matrix and sections analyzed, not in scale (d).

Each casting obtained two bars (dimensions $25 \mathrm{~mm} \times 125 \mathrm{~mm} \times 15 \mathrm{~mm}$ ), but only one bar was analyzed. Each rectangular-shaped casting was cut into three samples (25 $\mathrm{mm} \times 25 \mathrm{~mm} \times 10 \mathrm{~mm})$ for microstructural observations; these samples were grinded by $\mathrm{SiC}$ abrasive papers from 180 up to 2400 grit and then polished by cloths with diamond suspensions and colloidal silica. After polishing, samples were etched by Keller reagent and their microstructures were analyzed by using an optical microscope (LEICA MEF4M, Leica Microsystems, Heerbrugg, Switzerland). Note that samples have been taken from different parts of the casting, to highlight any possible variations in terms of 
microstructure, along with the mould. Silicon dimensions, as well as secondary dendrite arms spacings (SDAS), were measured on images $20 \times$ of magnification by the microscope-image-analysis software (LEICA QWin, version 3.5, Leica Microsystems, Heerbrugg, Switzerland) and compared between the different castings. Alloys' hardness was measured by utilizing micro-hardness Vickers (15 s, 500 gf-HV $0.5)$, to correlate the effects of the additive additions on the silicon size and SDAS size, by LEICA VMHT, Leica Microsystems, Heerbrugg, Switzerland apparatus. Micro-hardness is an average of values measured by an indentation matrix $3 \times 3$. Measures were performed in all the specimens. Silicon size was measured by image analysis, performed in three different parts of the samples, utilizing optical images (magnification 50×). SDAS measures were conducted in three different parts of the samples, measuring ten dendrites for each optical image (magnification 10x). Measurements were obtained by measuring the distance between the middle of two secondary dendrites arms, in the direction of the primary direction, as further shown in Figure 3.

In regard to microstructures, alloy EN AC 45300 belongs to the hypoeutectic system Al-Si and is suitable for both mould and sand castings; its composition contains relatively high amounts of $\mathrm{Cu}$ and $\mathrm{Mg}$, enabling the nucleation of intermetallic phases as $\theta-\mathrm{Al}_{2} \mathrm{Cu}, \mathrm{Al}_{2} \mathrm{CuMg}, \beta-\mathrm{Mg}_{2} \mathrm{Si}$, and $\mathrm{Q}-\mathrm{Al}_{5} \mathrm{Cu}_{2} \mathrm{Mg}_{8} \mathrm{Si}_{6}$ [27]. Furthermore, Fe lead to the nucleation of intermetallics, such as $\alpha-\mathrm{Al}_{8} \mathrm{Fe}_{2} \mathrm{Si}_{\text {, }}$ $\beta-\mathrm{Al}_{5} \mathrm{FeSi}, \pi-\mathrm{Al}_{8} \mathrm{Mg}_{3} \mathrm{FeSi}_{6}$, and $\mathrm{Al}_{9} \mathrm{FeMg}_{3} \mathrm{Si}_{5}$, while $\mathrm{Mn}$ allows the nucleation of Chinese-script-like $\alpha-\mathrm{Al}_{15}(\mathrm{Mn}, \mathrm{Fe})_{3} \mathrm{Si}_{2}$ intermetallic [28].

On the contrary, alloy EN AC 43500 can only form intermetallics Fe, Mn, and Mg-based [12,29]. This alloy is largely used for high-pressure die casting but is suitable for all types of casting. Details about intermetallic phases detected are shown in Figure 3.
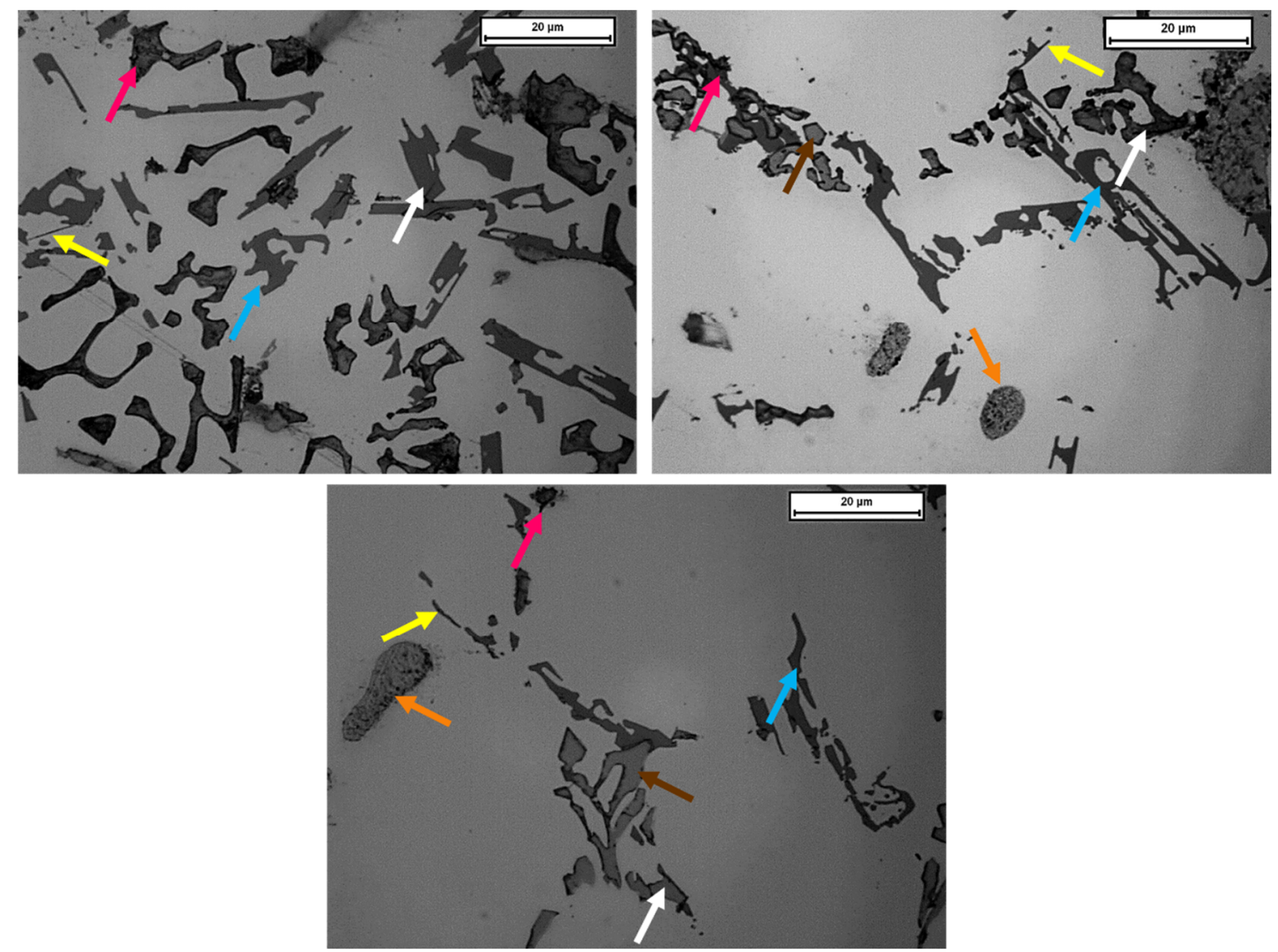

Figure 3. Optical microscope images of alloy EN AC 45300 (100× magnification, marker $20 \mu \mathrm{m})$. Microstructures and intermetallic phases. Blue = Eutectic silicon; purple = Mg-based phase; white = Q-phase; brown $=\alpha-\mathrm{Fe}$; yellow $=\beta-\mathrm{Fe}$; orange $=\mathrm{Al}-\mathrm{Al}_{2} \mathrm{Cu}-\mathrm{Si}$. 
Experimental quantitative data from image analysis were finally treated by ANOVA, to give robust evidence of which microstructural features were mostly affected by the use of casting additives. The software Minitab (v.2017-Minitab, LLC, Pennsylvania, USA) was adopted for data analysis. The condition of the alloy was isolated as a factor, capable of assuming three states (without additives, with refiner, refined, and modified), while SDAS, micro-hardness, and intermetallic size were treated as separate responses. Normality and equal variance assumption were adopted, and the $p$-value was calculated with $90 \%$ confidence interval (c.i.) for each sample. A $p$-value below 0.1 indicates that a significative difference in the measured property is detectable between the alloy without additives and the alloy with additives.

\section{Results and Discussion}

\subsection{Micro-Hardness and SDAS}

The results reported in Table 2 were obtained from micro-hardness measurements performed in the middle of the specimens. The casting agents do not seem to influence the micro-hardness values in the same alloy; nevertheless, there is a significant difference between the two alloys in terms of micro-hardness. EN AC 45300 is highly alloyed if compared to the poorly alloyed EN AC 43500; consequently, its hardness is higher. On average, adding a casting additive to the alloys results in a decrease of the variability of the measured hardness: Refined + modified alloys, in particular, show the lowest standard deviation (Table 2). This behavior was probably due to an inhomogeneous microstructure when additives are not used, as observed, for instance, with the same specimen, in Figure 4. For the alloy EN AC 43500, the high standard deviation is due to the microstructural inhomogeneities, while for EN AC 45300, the non-uniformity resulting in a high standard deviation is due to the random indentation of both the harder intermetallic phases and the softer $\alpha$-aluminium.

Table 2. Micro-hardness HV0.5 measures.

\begin{tabular}{ccc}
\hline HV0.5 & EN AC 45300 & EN AC 43500 \\
\hline No-Additives & $92.21 \pm 7.28$ & $76.99 \pm 5.69$ \\
\hline Refining & $91.42 \pm 4.26$ & $78.52 \pm 4.09$ \\
\hline Refining + Modification & $89.11 \pm 4.05$ & $80 \pm 1.81$ \\
\hline
\end{tabular}
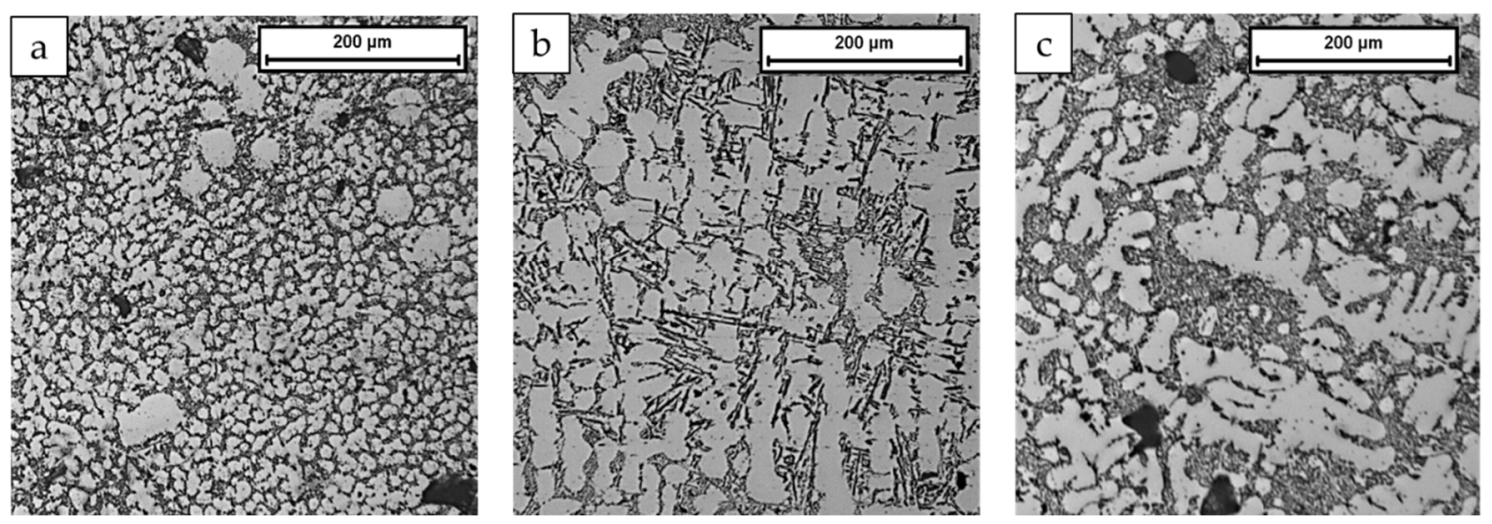

Figure 4. Optical images (10× magnification) of inhomogeneities in the microstructure of alloy EN AC 43500 without casting additives: (a) near the mould walls; (b) middle of the casting; (c) other regions of the casting.

Secondary dendritic arm spacing (SDAS) measurements were performed to detect the possible effects of the refining agent on the size of the dendrites. On the one hand, the EN AC 45300 alloy showed a decrease in SDAS size, from an average value of 28.62 to $23.33 \mu \mathrm{m}$, after adding a refiner, as 
shown in Figure 5. Moreover, a supplementary decrease of SDAS seems to occur with the addition of the modification agent.

On the other hand, 250 ppm of refiner did not influence the SDAS in the EN AC 43500 alloy, confirming that $250 \mathrm{ppm}$ of refiner is not enough to refine the microstructure. For this alloy, the addition of the modification agent, too, did not seem to influence the SDAS.
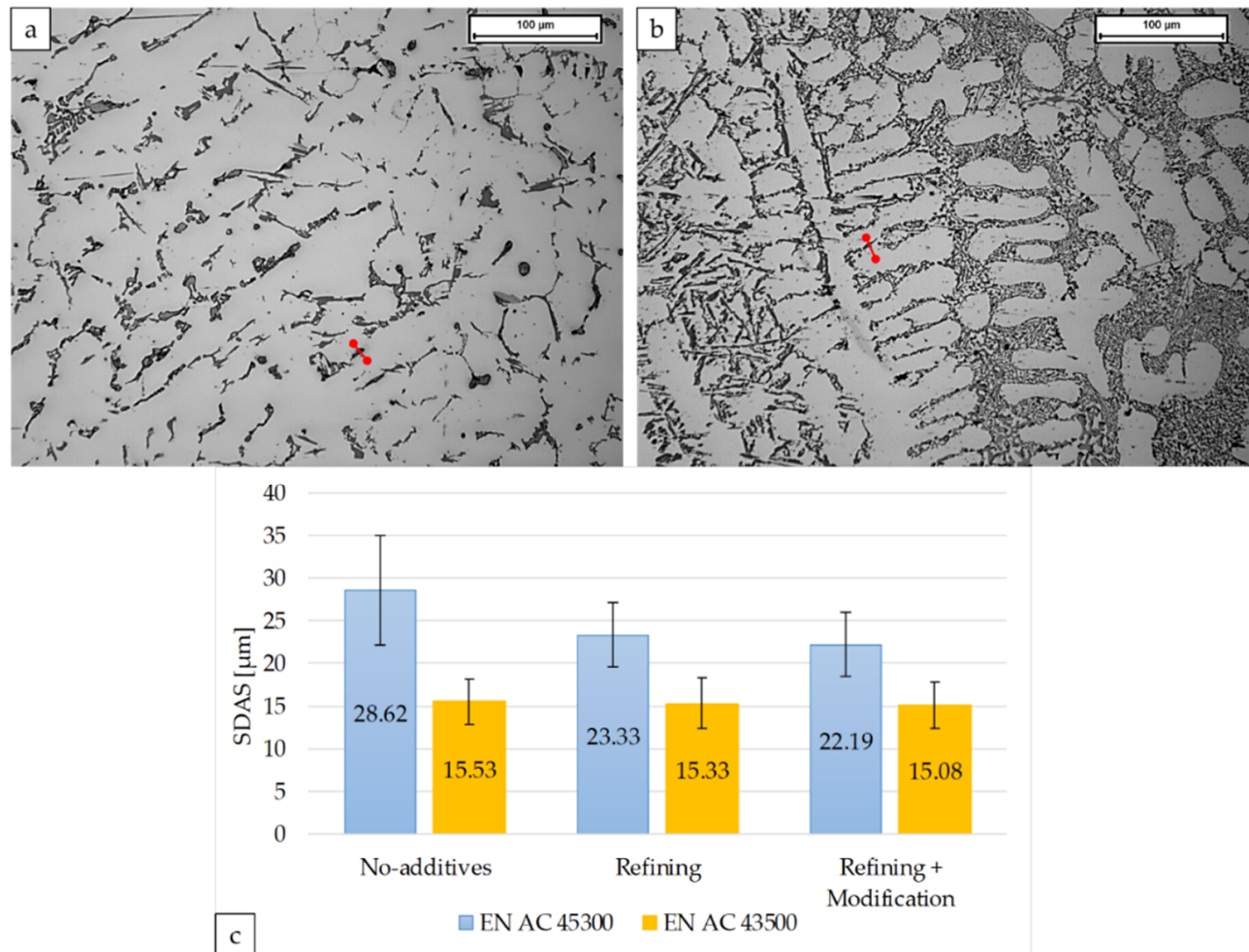

Figure 5. SDAS measured into the alloys' bulk. Red lines in $(\mathbf{a}, \mathbf{b})$ indicate the measuring method. Optical image 10× of alloy EN AC 45300 alloy (a); optical image 20× of alloy EN AC 43500 (b); SDAS measurements (c).

\subsection{Eutectic Silicon and Intermetallic Phases}

Refining and modification treatments led to variations in microstructure aspects. The reduction in SDAS after the adoption of refining agents is well-known and was demonstrated in Figure 4, as the further addition of modification agent may influence other microstructure features, such as, for instance, silicon shape. Microstructures showed in Figure 6 refer to the EN AC 43500 alloy in a refined state and to the EN AC 45300 alloy in the refined and modified state. In the central part of the samples, silicon resulted in uneven shape (Figure $6 a, b$ ), but also some casting defects were observed, such as coarse-Fe intermetallics (a), interdendritic shrinkage (b), and bifilm (c). Particularly, bifilm was detected in EN AC 45300 alloy only. In this regard, defects and coarse intermetallics may influence the micro-hardness values, as noticed by the high standard deviation in Table 2. Eutectic silicon shape affects the mechanical properties of the alloys, especially in terms of stress concentration [12]; in the case of mechanical solicitations, acicular silicon can behave as a stress concentrator, guiding the growth of cracks along a preferential low-energy path. For this purpose, in order to change silicon morphology, additives were used. From the image analysis performed in the bulk of the samples, some considerations can be given. 

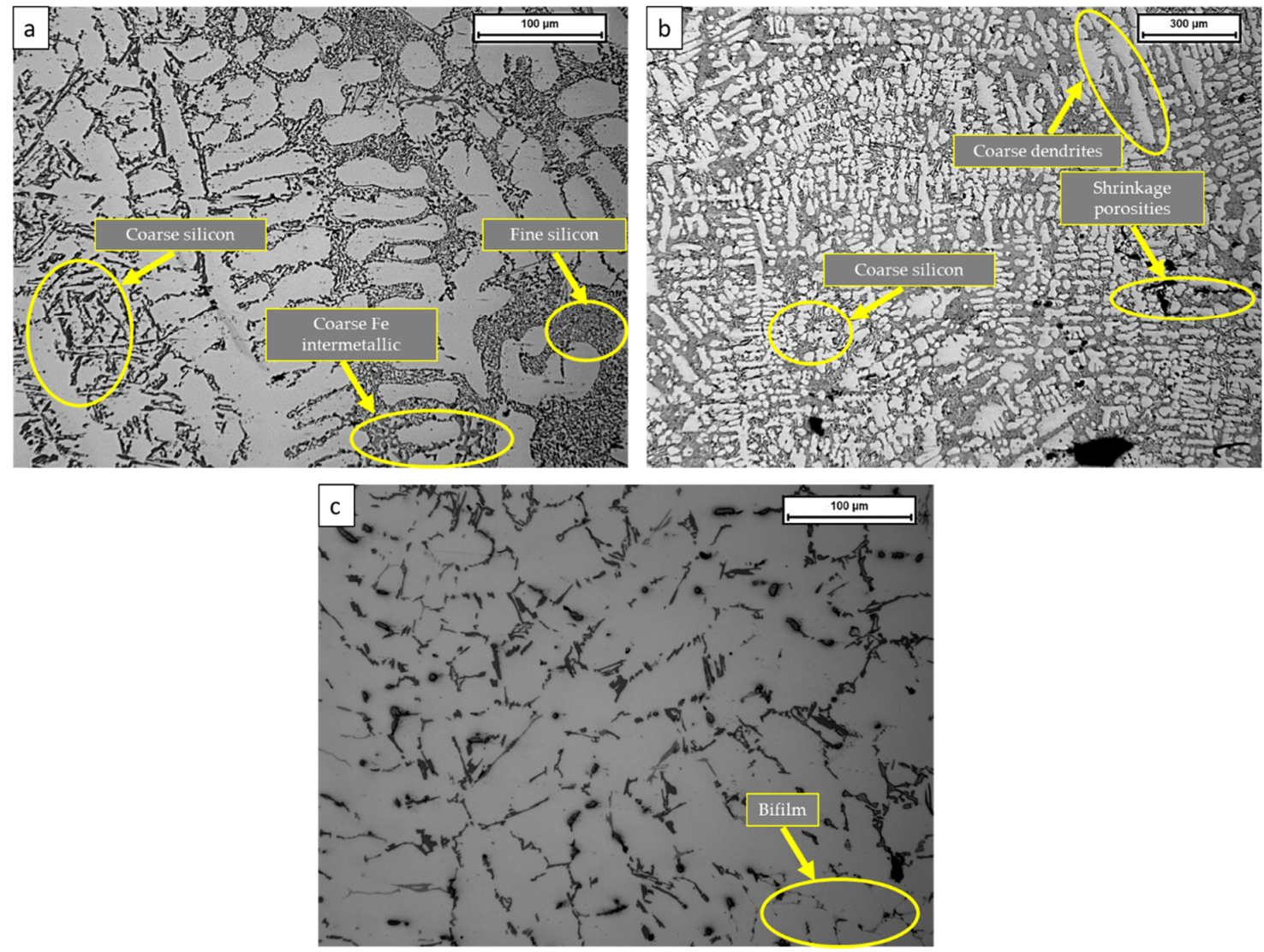

Figure 6. Optical microscope images (a-c). Defects in alloy EN AC 43500 refined (a,b) and alloy EN AC 45300 refined and modified (c).

Intermetallic particles and silicon particles were measured via image analysis, and the results are reported in Figure 7. It was not possible to classify these particles on a composition-based scale by image analysis, so the average particle size for all phases was considered. The average particle's area is higher for EN AC 45300 alloy than for EN AC 43500 alloy. In regard to EN AC 43500, it seems that only the addition of both refiner and modifier permits a reduction of average particles area (about $40 \%$ ), while with the sole use of the refiner, a slight increase in particles size was detected. In alloy EN AC 45300 , only a decrease of particles size was noticed.

The average particles area decrease can be attributed to both silicon's size decreasing and intermetallics' size decreasing. In this sense, it could be useful to measure the average areas for different intermetallic phases. For instance, Fe-intermetallic phases are represented by $\alpha-\mathrm{Al}(\mathrm{Fe}, \mathrm{Mn}) \mathrm{Si}$, typical light-gray polygonal-shaped intermetallic phases. This intermetallic was observed in both alloys.

Only the alloy EN AC 43500 showed a reduction in the average intermetallic area by the mere addition of a refiner (Figure 8), meaning that additives may influence some Fe-intermetallic phases in terms of occupied area. This reduction was about $52 \%$ with refiner only and about $24 \%$ with both the refiner and the modifier.

The opposite behavior was detected in the EN AC 45300 alloy, where intermetallic areas increased by $29 \%$ and $9 \%$, respectively. The very high standard deviations are evident from the normal distributions for both alloys, indicating a large dispersion of the intermetallic dimensions detected.

As the intermetallic phase $\beta-\mathrm{Al}_{9} \mathrm{FeSi}$, area measurement undergoes a gradual variation, as shown in Figure 9. Totally, in alloy EN AC 43500, the addition of 250 ppm of Al-Ti-B seems to be effective in influencing the $\beta$-Fe intermetallic areas, with an average reduction of $21 \%$ of the intermetallic areas, while the additions of $250 \mathrm{ppm}$ of Al-Ti-B and $250 \mathrm{ppm}$ Al-Sr10 lead to a decrease of $47 \%$. On the other hand, in the EN AC 45300, alloy contradictory pieces of information were observed: the adoption 
of $250 \mathrm{ppm}$ of Al-Ti-B seems to lead to a decrease of the $\beta$-Fe intermetallic areas of $24 \%$, while the additions of $250 \mathrm{ppm}$ of Al-Ti-B and $250 \mathrm{ppm}$ of Al-Sr10 lead to an increase of $64 \%$. The large standard deviation, especially in EN AC 45300, leads to high kurtosis of the distribution.

$\mathrm{Mg}_{2} \mathrm{Si}$ phase is present in both alloys, and the results are shown in Figure 10. For EN AC 45300 without additives, the standard deviations of the average intermetallic area is very large, as demonstrated by the high kurtosis in the distribution of the measured areas. In EN AC 43500, the standard deviations are smaller, and phases are characterized by a minor average area. For this alloy, it seems that the addition of Sr leads to a strong decrease in the average area.
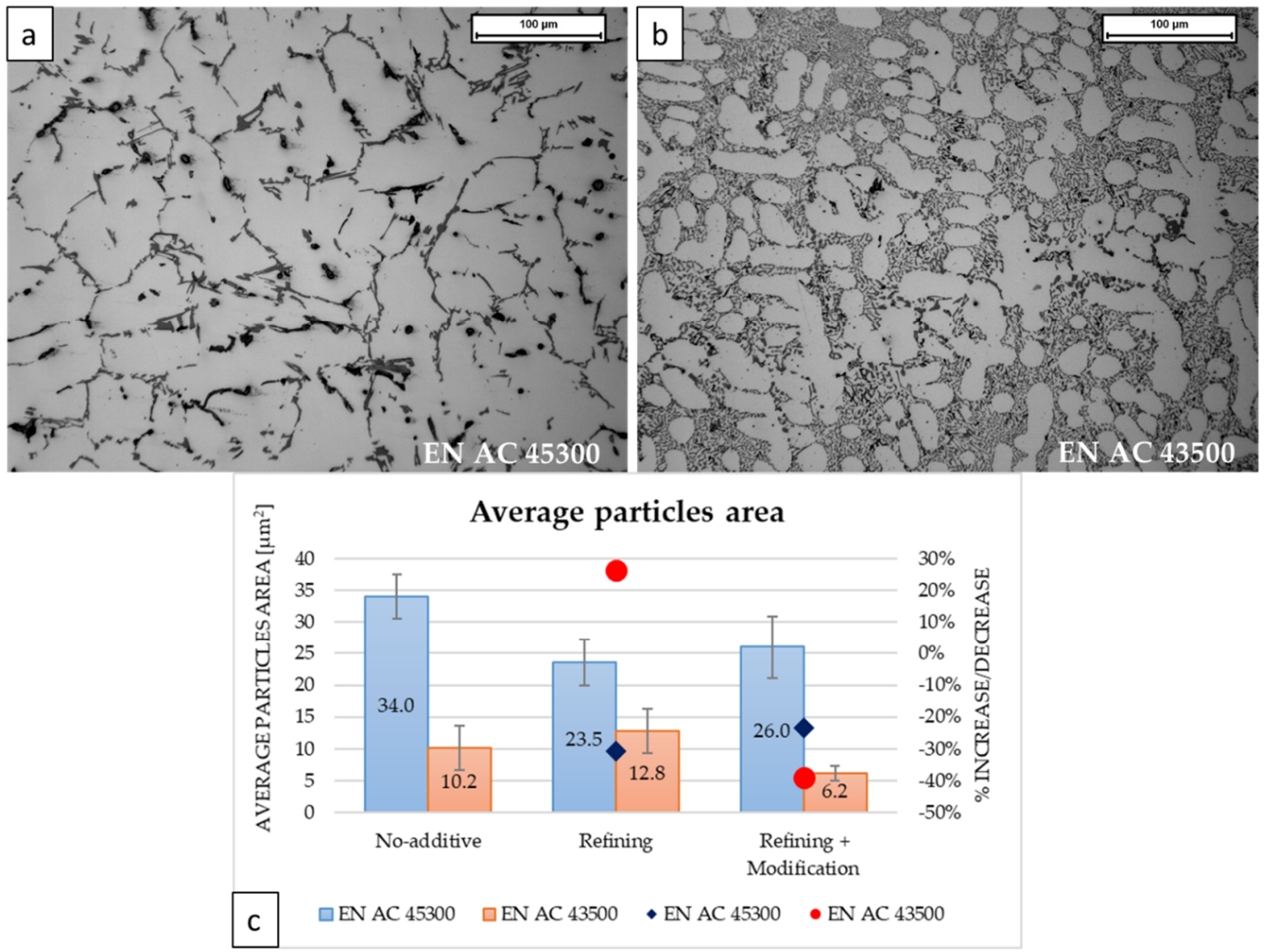

Figure 7. Average particles area measured by image analysis in both alloys. Microstructure in alloy EN AC 45300 without additives (a); microstructure in alloy EN AC 43500 without additives (b); bar chart shows the average values and standard deviations (c). Points in bar chart highlight the increase or decrease of the particles' area in percentage terms, concerning the pure alloy.

$\mathrm{Cu}$-based intermetallics are only present in alloy EN AC 45300. However, given that $\mathrm{Al}_{2} \mathrm{Cu}$ phase is usually very small, histograms in Figure 11 show the average measurements obtained by measuring the $\mathrm{Al}-\mathrm{Al}_{2} \mathrm{Cu}-\mathrm{Si}$ phase. In this case, average values are very close: A decrease of $13 \%$ in the fraction of measured particles was observed after the Al-Ti-B addition, while an increase of $4 \%$ was observed when both Al-Ti-B and Al-Sr10 were added. The normal distribution curves are similar to each other because the standard deviation measurements are similar. It seems there is no substantial modification of the average area of this intermetallic phase.

Considering all the intermetallic particles measured ( $\alpha-\mathrm{Fe}, \beta-\mathrm{Fe}, \mathrm{Mg}_{2} \mathrm{Si}$, and $\mathrm{Al}_{-}-\mathrm{Al}_{2} \mathrm{Cu}-\mathrm{Si}$ ), it is possible to compare the total average for each sample, with respect to the average values for all particles (Figure 7). The results obtained from this comparison are reported in Figure 12. 

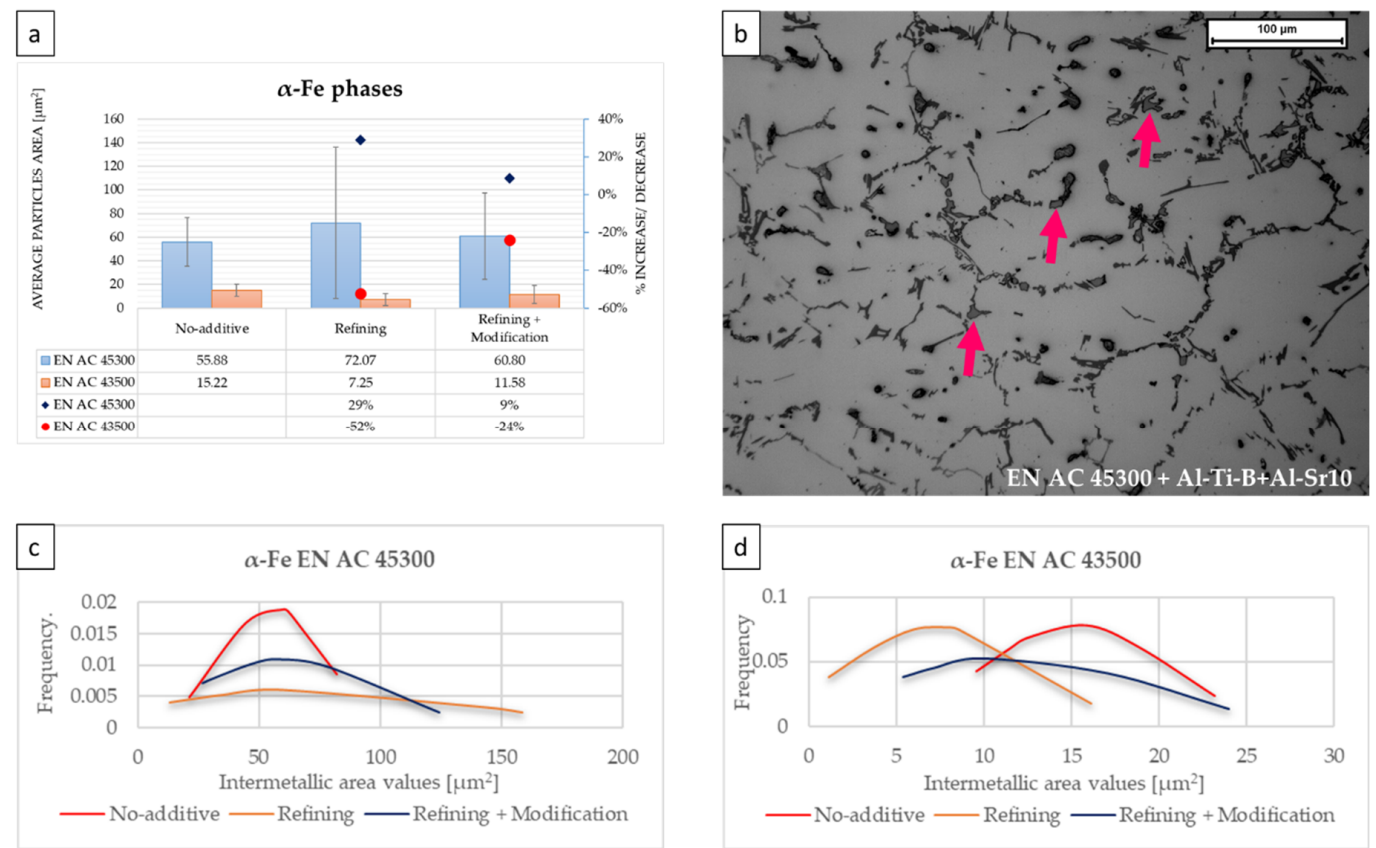

Figure 8. The average $\alpha$-Fe area measured by image analysis in both alloys. In the bar chart, the average values and standard deviations are reported (a). Single points highlight the increase or decrease of the particles area in percentage terms, in respect to the no-additive status. Microstructure evidenced the phase shape (b). The graphs in the lower part show the particle size distribution of the phase measured (c,d).
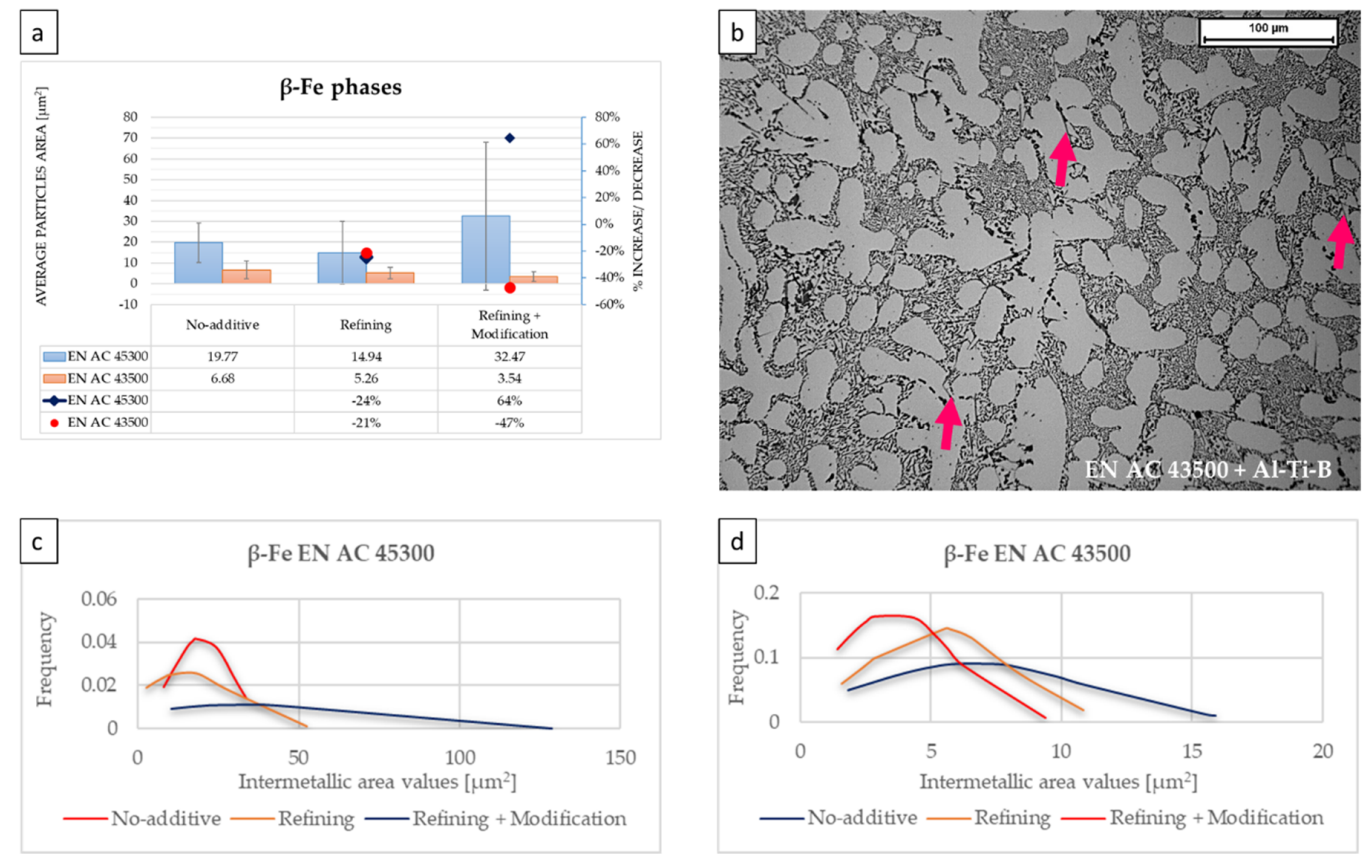

Figure 9. The average $\beta$-Fe area measured by image analysis in both alloys. The bar chart shows the average values and standard deviations (a). Points highlight the increase or decrease of the particles' area in percentage terms, in respect to the no-additive status. Microstructure evidenced the phase shape (b). The graphs in the lower part show the particle size distribution concerning the phase measured $(\mathbf{c}, \mathbf{d})$.

Samples cast without additives, called no-additive, showed an average particles area very similar to the average obtained by averaging all intermetallic measurements: $36.5 \mu \mathrm{m}^{2}$ and $34 \mu \mathrm{m}^{2}$ respectively 
for alloy EN AC 45300, and $10.2 \mu \mathrm{m}^{2}$, in both cases, for EN AC 43500. This means that the usage of additives influences all particles presents, as already noticed by the analysis conducted on principal phases, and this behavior is most striking for alloy EN AC 45300.
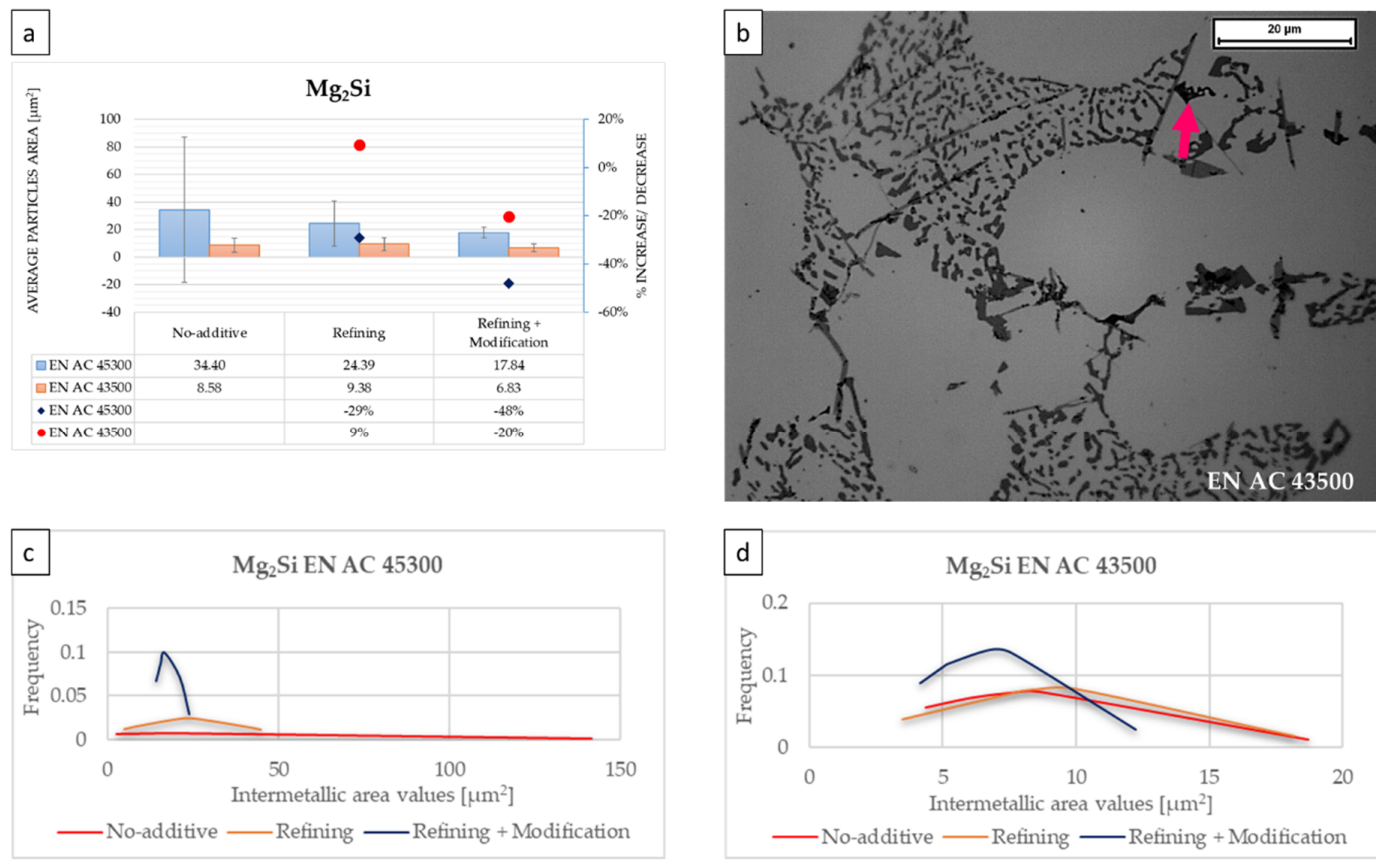

Figure 10. The average $\mathrm{Mg}_{2} \mathrm{Si}$ area measured by image analysis in both alloys. Bar chart showed the average values and standard deviations (a). Points highlight the increase or decrease of the particles' area in percentage terms, in respect to the no-additive status. Microstructure evidenced the phase shape (b). The graphs in the lower part show the particle size distribution concerning the phase measured (c,d).
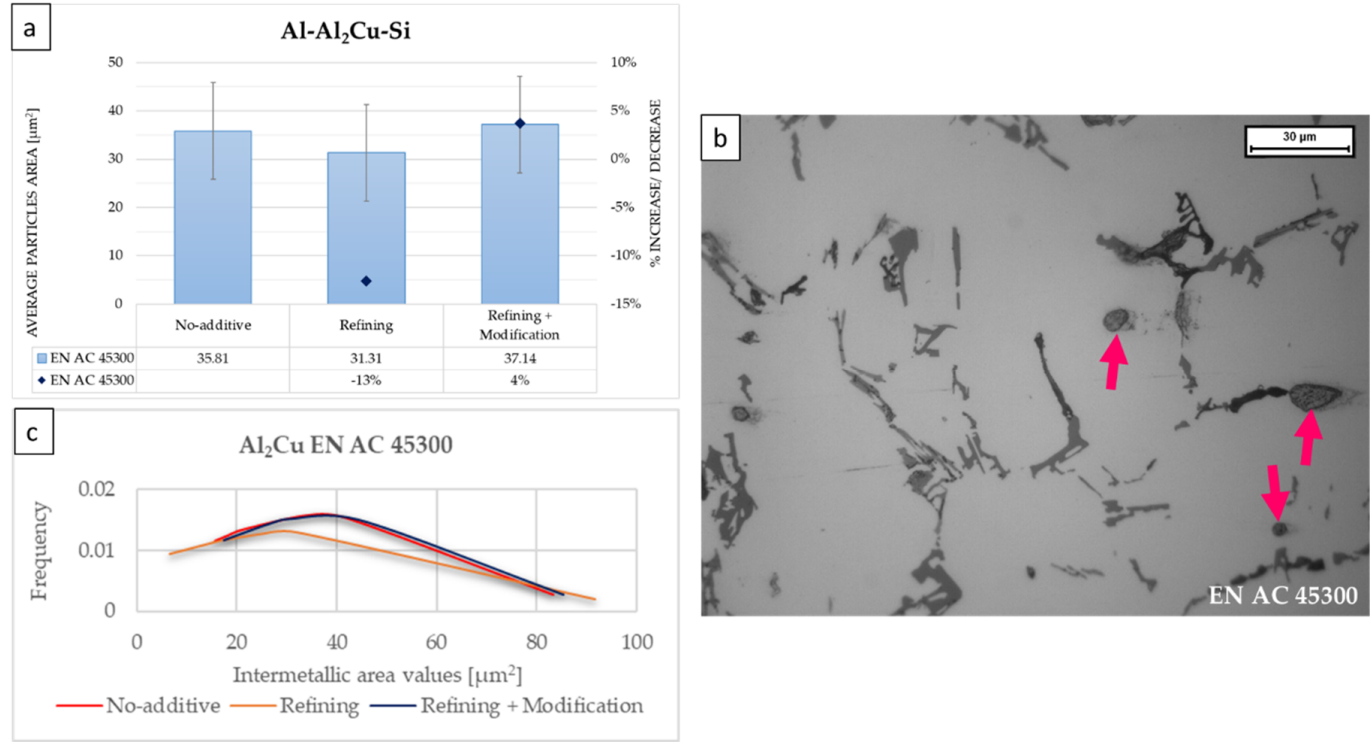

Figure 11. The average $\mathrm{Al}-\mathrm{Al}_{2} \mathrm{Cu}-\mathrm{Si}$ area measured by image analysis. Bar chart shows the average values and standard deviations (a). Points highlight the increase or decrease of the particles area in percentage terms, in respect to the no-additive status. Microstructure evidenced the phase shape (b). The graph in the lower part shows the normal particle size distribution concerning the phase measured (c). 


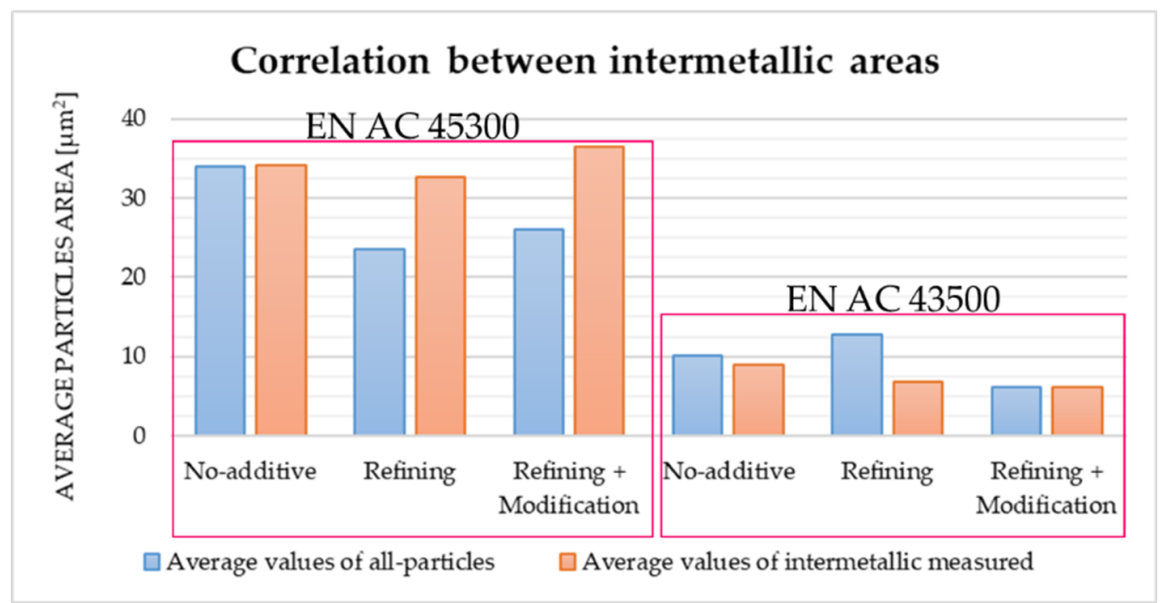

Figure 12. Correlation between general intermetallic phase areas of Figure 6 (blue bars) and average measured for other intermetallic phases of Figures 7-10 (orange bars).

\subsection{Data Treatment with ANOVA}

After having shown and discussed data in detail in the previous paragraphs, a resuming table with synoptic intent is proposed; for this reason, data were treated with ANOVA [30,31]. In Table 3, the results of the $p$-value confirm that some significative microstructural differences arise due to the adoption of casting additives. The $p$-values reported in the table suggest that casting additives have a significant effect on SDAS for both alloys $(p<0.1)$, while hardness is slightly affected for the EN AC 43500, due to microstructural casting defects, rather than due to real microstructural modifications due to the additives action. With regards to intermetallics size, different behaviors were detected: $\mathrm{Mg}_{2} \mathrm{Si}$ and $\mathrm{Al}-\mathrm{Al}_{2} \mathrm{Cu}-\mathrm{Si}$ do not seem to be affected at all by the use of casting additives $(p>0.1)$, while the effect is different in the two alloys for $\alpha$-Fe and $\beta$-Fe.

Table 3. The $p$-values with $90 \%$ c.i. for the different responses calculated from ANOVA.

\begin{tabular}{ccc}
\hline Measured Parameters & EN AC 45300 & EN AC 43500 \\
\hline HV_0.5 & 0.461 & 0.048 \\
\hline SDAS & 0.001 & 0.001 \\
\hline$\alpha-\mathrm{Fe}$ & 0.821 & 0.103 \\
\hline$\beta-\mathrm{Fe}$ & 0.046 & 0.228 \\
\hline $\mathrm{Mg}_{2} \mathrm{Si}$ & 0.673 & 0.603 \\
\hline $\mathrm{Al}-\mathrm{Al}_{2} \mathrm{Cu}-\mathrm{Si}$ & 0.928 & - \\
\hline
\end{tabular}

To understand the effect of casting additives on single intermetallics, tailored studies have to be undertaken, by varying the quantity of additives. Further efforts will be made in future works to establish more extensive correlations and derive general predictive equations correlating the effect of the quantity of the single casting additive in modifying the microstructure of aluminum alloys.

\section{Conclusions}

In this work, the effects of the refining agent Al-Ti-B, alone or in combination, with the modifying agent Al-Sr10, were studied. The casting additives were used into two Al-Si alloys, to evaluate their effect, depending on the alloys' silicon content and on the alloying elements, and the following results were found.

It seems that the addition of both refining and refining + modify agents does not influence the micro-hardness of the alloys. In fact, both the alloys show almost the same micro-hardness values of 
about 90 HV0.5 for EN AC 45300 and 80 HV0.5 for EN AC 43500, regardless of the casting additives. The high standard deviations were due to inhomogeneous microstructures, especially for alloy EN AC 45300, which contains hard intermetallic phases (Table 2).

Alloy EN AC 45300 shows a decrease in SDAS size, from an average value of 28.62 to $23.33 \mu \mathrm{m}$, with the addition of a refiner. Moreover, a supplementary decrease of SDAS seems to take place with the addition of the modification agent. On the other hand, this effect was not detected in alloy EN AC 43500. This result highlights that the refiner agent resulted in a non-appropriate amount to properly refine the alloy's microstructure.

As demonstrated in [32], Sr influences both the needle-like iron-rich intermetallics ( $\beta-\mathrm{Fe})$, causing their fragmentation and reduction in length and the decreasing in size and number of $\alpha$-Fe intermetallics. This behavior has been confirmed in alloy EN AC 43500; furthermore, it seems that Al-Ti-B has similar effects. On the other hand, this attitude was not confirmed in alloy EN AC 45300.

The $\mathrm{Mg}_{2} \mathrm{Si}$ phase is present in both alloys. In regard to EN AC 43500, it seems that the addition of $\mathrm{Sr}$ leads to a strong decrease in the average area. On the other hand, in alloy EN AC 45300, both the additives seems to act on this intermetallic phase, reducing its dimensions.

In the case of the intermetallic phase $\mathrm{Al}_{2} \mathrm{Cu}$, which is only present in EN AC 45300 alloy, the normal distribution curves are similar to each other, highlighting no substantial modification of the average area of this intermetallic phase.

The comparison made between average particles' area measured and the average value, considering all intermetallic areas, was performed and shown in Figure 12. Additions of additives cause a variation between these values, especially for alloy EN AC 45300, evidencing the effect of refiner and modifier on the silicon shape.

This work focused on the evolution of the intermetallic phases. Despite that, it is important to note that this evolution can impact other mechanical properties. In particular, the spheroidisation of the eutectic silicon, along with the SDAS reduction and the fragmentation of $\beta$-Fe intermetallic phases, has a beneficial effect on the mechanical resistance, as demonstrated in Reference [12], referring to the impact properties, and in Reference [33], on tensile properties, especially if a heat treatment takes place. For these reasons, further investigations on mechanical properties of these alloys, as well as fracture analysis, will be conducted, with the aim to link the fracture mechanism and the mechanical properties observed with the analysis here performed.

In conclusion, Al-Ti-B acts on aluminium-silicon alloys, affecting the SDAS measures, especially in alloys with a lower silicon content. The lack of homogeneity affected, in particular, the measurements in alloy EN AC 45300. From these results, it can be concluded that the size of some intermetallic phase can be reduced by employing additives, and, in this regard, positive results were observed just by adding $250 \mathrm{ppm}$ of additives.

Author Contributions: Conceptualization, E.F. and M.R.; methodology, E.E.; formal analysis, E.F. and F.S.G.; investigation, E.F. and F.S.G.; data curation, E.F. and F.S.G.; writing-Original draft preparation, E.F. and F.S.G.; writing-Review and editing, M.R.; supervision, M.R. All authors have read and agreed to the published version of the manuscript.

Funding: This research received no external funding.

Acknowledgments: The authors would like to thank Nicolò Arcieri for help in samples' preparation.

Conflicts of Interest: The authors declare no conflict of interest.

\section{References}

1. Hertwich, E.G.; Ali, S.; Ciacci, L.; Fishman, T.; Hereen, N.; Masanet, E.; Asghari, F.N.; Olivetti, E.; Pauliuk, S.; $\mathrm{Tu}, \mathrm{Q}$.; et al. Material efficiency strategies to reducing greenhouse gas emissions associated with buildings, vehicles and electronics-A review. Environ. Res. Lett. 2019, 14, 043004. [CrossRef] 
2. Darmani, M.A.; Poskovic, E.; Bramerdorfer, G.; Vaschetto, S.; Cavagnino, A.; Tenconi, A. Surface-mounted and flux-switching PM structures trade-off for automotive smart actuators. In Proceedings of the Eleventh Annual IEEE Energy Conversion Congress and Exposition (ECCE 2019), Baltimore, MD, USA, 29 September-3 October 2019; pp. 6555-6561. [CrossRef]

3. Poskovic, E.; Ferraris, L.; Franchini, F.; Cavagnino, A.; Actis Grande, M. SMC materials in electrical machine prototypes. In Proceedings of the 2019 IEEE International Electric Machines \& Drives Conference (IEMDC), San Diego, CA, USA, 12-15 May 2019; pp. 2042-2047. [CrossRef]

4. Ajanovic, A.; Haas, R. Economic and Environmental Prospects for Battery Electric- and Fuel Cell Vehicles: A Review. Fuel Cells 2019, 19, 515-529. [CrossRef]

5. Apelian, D. Looking beyond the last 50 years: The future of materials science and engineering. J. Miner. Met. Mater. Soc. 2007, 59, 65-73. [CrossRef]

6. Tanwir, A.; Ansari, A. Review on Aluminium and Its Alloys for automotive applications. J. Adv. Technol. 2017, 5, 278-294.

7. Peter, I.; Fracchia, E.; Canale, I.; Maiorano, R. Incremental sheet forming for prototyping automotive modules. Procedia Manuf. 2019, 32, 50-58. [CrossRef]

8. Pacana, A.; Czerwinska, K.; Bednarova, L. Discrepancies analysis of casts of diesel engine piston. Metal 2018, 57, 324-326.

9. Javidani, M.; Larouche, D. Application of cast Al-Si alloys in internal combustion engine components. Int. Mater. Rev. 2014, 59, 132-158. [CrossRef]

10. Fracchia, E.; Gobber, F.; Rosso, M. About weldability and welding of Al alloys: Case study and problem solving. J. Achiev. Mater. Manuf. Eng. 2017, 2, 67-74. [CrossRef]

11. Fracchia, E.; Lombardo, S.; Rosso, M. Case Study of a Functionally Graded Aluminum Part. Appl. Sci. 2018, 8, 1113. [CrossRef]

12. Fracchia, E.; Gobber, F.S.; Rosso, M.; Actis Grande, M.; Bidulská, J.; Bidulský, R. Junction characterization in a functionally graded aluminum part. Materials 2019, 12, 3475. [CrossRef] [PubMed]

13. Rosso, M.; Lombardo, S.; Gobber, F. Sequential Gravity Casting in Functionally Graded Aluminum Alloys Development. Miner. Met. Mater. Soc. 2017, 2017, 877-883. [CrossRef]

14. Lombardo, S.; Peter, I.; Rosso, M. Gravity Casting of Variable Composition Al Alloys: Innovation And New Potentialities. Mater. Today Proc. 2017, 10, 271-276. [CrossRef]

15. Fracchia, E.; Gobber, F.S.; Lombardo, S.; Rosso, M. Colata per gravità di un FGM in lega di alluminio: Ottimizzazione del trattamento termico e proprietà finali. La Metallurgia Italiana 2019, 4, 5-12.

16. Samuel, A.M.; Doty, H.W.; Valtierra, S.; Samuel, F.H. Effect of grain refining and Sr-modification interactions on the impact toughness of Al-Si-Mg cast alloys. Mater. Des. 2014, 56, 264-273. [CrossRef]

17. Firouzdor, V.; Rajabi, M.; Nejati, E.; Khomamizadeh, F. Effect of microstructural constituents on the thermal fatigue life of A319 aluminum alloy. Mater. Sci. Eng. A 2007, 454, 528-535. [CrossRef]

18. Samuel, A.M.; Mohamed, S.S.; Doty, H.W.; Valtierra, S.; Samuel, F.H. Some aspects of grain refining of Al-Si cast alloys. Int. J. Cast Met. Res. 2018, 32,1-14. [CrossRef]

19. Jasim, T.A. Review on the Mechanisms of Modification Al-Si alloys. J. Univ. Babylon Eng. Sci. 2019, 27, 338-343. [CrossRef]

20. Mrówka-Nowotnik, G. Intermetallic Phases Examination in Cast AlSi5Cu1Mg and AlCu4Ni2Mg2 Aluminium Alloys in As-Cast and T6 Condition. In Recent Trends in Processing and Degradation of Aluminium Alloys; IntechOpen: Rijeka, Croatia, 2011.

21. Brůna, M.; Bolibruchová, D.; Kantorík, R. Filtration of aluminum alloys and its influence on mechanical properties and shape of eutectical silicium. Arch. Foundry Eng. 2008, 8, 13-16.

22. Limmaneevichitr, C.; Eidhed, W. Fading mechanism of grain refinement of aluminum-silicon alloy with Al-Ti-B grain refiners. Mater. Sci. Eng. A. 2003, 349, 197-206. [CrossRef]

23. Lombardo, S.; Fracchia, E.; Gobber, F.; Rosso, M. Gestione delle conchiglie nella colata in gravità e possibili vie per migliorarne prestazioni e durata. La Metallurgia Italiana 2019, 6, 6.

24. Fracchia, E.; Gobber, F.; Lombardo, S.; Rosso, M. Paint characterization to improve the mould durability in the aluminum gravity casting. In Proceedings of the Aluminum Two Thousand, Trevisio, Italy, 9-13 April 2019.

25. Gobber, F.S.; Pisa, A.G.; Ugues, D.; Rosso, M. Design of a Test Rig for the Characterization of Thermal Fatigue and Soldering Resistance of the Surfaces of Tool Steels for High-Pressure Die-Casting Dies. Steel Res. Int. 2019, 91, 1900480. [CrossRef] 
26. Gobber, F.; Pisa, A.; Ugues, D.; Lombardo, S.; Fracchia, E.; Rosso, M. Study of the Effect of Surface-Roughness of Dies and Tooling for HPDC on Soldering. Light Met. 2018, 977-981. [CrossRef]

27. Yu, B.B.; Yan, H.; Zhu, J.B.; Liu, J.L.; Li, H.G.; Nie, Q. Effects of La on Microstructure and Corrosion Behavior of AlSi5Cu1Mg Alloy. Acta Metall. Sin. 2019, 32, 443-451. [CrossRef]

28. Zhu, J.; Luo, Z.; Wu, S.; Yan, H. The effect of Sr on the microstructure and wear properties of AlSi5Cu1Mg alloy. Adv. Mech. Eng. 2018, 10, 1-10. [CrossRef]

29. Berlanga, C.; Bakedano, A.; Perez de Ciriza, A.; Rivero, P.J.; Mendez, S.; Rodriguez, R.; Niklas, A. Evaluation of the corrosion resistance of a new AlSi10MnMg(Fe) secondary alloy. Mater. Today Proc. 2019, 10, 312-318. [CrossRef]

30. Puerta-Morales, F.J.; Gomez, J.S.; Fernandez-Vidal, S.R. Study of the influence of helical milling parameters on the quality of holes in the UNS R56400 alloy. Appl. Sci. 2020, 10, 845. [CrossRef]

31. Grosselle, F.; Timelli, G.; Bonollo, F. Doe applied to microstructural and mechanical properties of Al-Si-Cu-Mg casting alloys for automotive applications. Mater. Sci. Eng. A 2010, 527, 3536-3545. [CrossRef]

32. Espinoza-Cuadra, J.; Gallegos-Acevedo, P.; Mancha-Molinar, H.; Picado, A. Effect of Sr and solidification conditions on characteristics of intermetallic in Al-Si 319 industrial alloys. Mater. Des. 2010, 31, 343-356. [CrossRef]

33. Shabestari, S.G.; Shahri, F. Influence of modification, solidification conditions and heat treatment on the microstructure and mechanical properties of A356 aluminum alloy. J. Mater. Sci. 2004, 39, 2023-2032. [CrossRef]

(C) 2020 by the authors. Licensee MDPI, Basel, Switzerland. This article is an open access article distributed under the terms and conditions of the Creative Commons Attribution (CC BY) license (http://creativecommons.org/licenses/by/4.0/). 